\title{
Avaliação da limpeza de equipamentos de hemodiálise pelo método de Lightning MVP ICON
}

\author{
Evaluation of the cleaning equipment of hemodialysis by method Lightning MVP ICON
}

\author{
Juliana de Oliveiraa, Roberta Monteiro Katzap ${ }^{b}$, Carlos Eduardo Poli de Figueiredoc, \\ Ana Elizabeth Figueiredo ${ }^{d}$

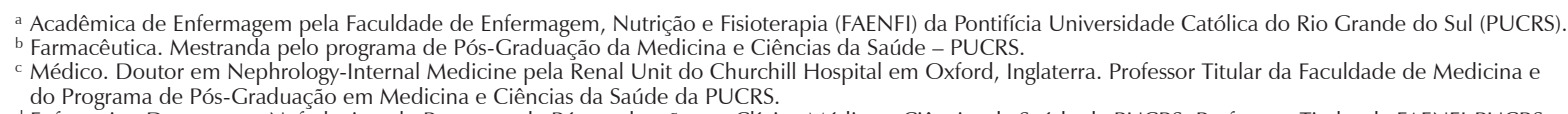 \\ d Enfermeira. Doutora em Nefrologia pelo Programa de Pós-graduação em Clínica Médica e Ciências da Saúde da PUCRS. Professora Titular da FAENFI-PUCRS.
}

Fontes de financiamento: Bolsa de estudo FAPERGS.

RESUMO Introdução: A higienização inadequada de superfícies é um fator contribuinte para a ineficácia no controle de infecções no ambiente hospitalar.

Objetivo: Avaliar a limpeza da superfície do equipamento de hemodiálise através do método de bioluminescência com o Lightning MVP ICON, antes e depois da higienização da máquina de hemodiálise.

Materiais e Métodos: Estudo transversal, realizado na unidade de hemodiálise do Hospital São Lucas da PUCRS. Foram coletadas amostras em 20 máquinas de hemodiálise em três turnos diferentes. Os swabs foram obtidos em 4 pontos pré-estabelecidos, os quais são: superfície superior, garra, setas de programação e botão ON/OFF, antes e depois da limpeza do equipamento, totalizando 480 pontos de coleta. Foi realizada a leitura para detecção de ATP com o equipamento Lightning MVP ICON, qualificando as amostras em: passou, alerta e falha.

Resultados: Verificamos diferença estatística significativa entre as avaliações antes e depois no local das setas de programação $(p=0,033)$, onde ocorreu um aumento significativo da classificação "Passou" depois da limpeza (48,3\% $(n=29))$ quando comparado ao momento anterior $(25,0 \%(n=15))$. Quando os resultados foram avaliados por turnos, o turno da noite (antes: $2,7 \pm 1,2$ vs. depois: 1,0 10,9 ) apresentou uma redução significativamente mais expressiva no número de falhas quando comparado aos turnos da manhã (antes: 2,2 $\pm 1,2$ vs. depois: 2,0 $\pm 1,2$ ) e da tarde (antes: $2,2 \pm 1,0$ vs. depois: $2,1 \pm 1,3$ ).

Conclusão: A utilização do método Lightning MVP ICON para avaliação da limpeza da superfície do equipamento de hemodiálise permitiu observar diminuição significativa do número de falhas de limpeza após higienização e ainda redução expressiva do número de falhas nos procedimentos realizados no turno da noite quando comparados com os turnos da manhã e tarde

Palavras-chave: diálise renal; bioluminescência; trifosfato de adenosina.

Introduction: Improper cleaning of surfaces is a contributing factor to inefficiency in infection control in the hospital environment. Objective: To evaluate the effectiveness of the hemodialysis machine cleaning using bioluminescence with the Lightning MVP ICON. Materials and Method: A cross-section study at the Hemodialysis unit of the Hospital São Lucas. Samples were collected in 20 machines in three different shifts. The swabs were obtained in 4 pre-determine points, which are: top surface, dialyzer holder, programming and ON/OFF arrows before and after cleaning of equipment, in total were 480 collection points. The reading was held for ATP detection with the Lightning MVP ICON equipment, describing the samples in passed, alert and failure.

Results: We found statistically significant differences between evaluations before and after in the case of the programming arrows $(p=0.033)$, where was a significant increase in the rating "passed" after [48.3\% $(n=29)]$ when compared to before [25.0\% $(n=15)]$. When the results were compared between shift, the night shift (before: $2.7 \pm 1.2 \mathrm{vs}$. after: 1.0 \pm 0.9 ) had a significantly reduction in the number of failures compared to morning shifts (before: $2.2 \pm 1.2$ vs. after: $2.0 \pm 1.2$ ) and afternoon shift (before: $2.2 \pm 1.0$ vs. after: $2.1 \pm 1.3)$.

Conclusion: The use of the Lightning MVP icon method to evaluate the surface cleaning of the hemodialysis equipment showed a significant decrease in the number of failures after cleaning and sanitizing and significant reduction on number of failures in procedures performed at the night shift when compared to the morning and afternoon shifts.

Keywords: kidney dialysis; bioluminescence; adenosine triphosphate. 


\section{INTRODUÇÃO}

Os pacientes com doença renal crônica em hemodiálise têm a sua imunidade prejudicada devido à própria doença, comorbidades e desnutrição. Este cenário contribui para que estes pacientes fiquem propensos às infecções virais, bacterianas e fúngicas ${ }^{1}$.

A assistência em saúde promove o aumento da disseminação de microrganismos com potencial patogênico para indivíduos imunologicamente vulneráveis. A falta de higienização das mãos, e dos materiais utilizados na assistência, são fatores que contribuem para a ineficiência no controle de infecção. A higienização inadequada de superfícies aumenta a probabilidade de contaminação e a disseminação de microrganismos patogênicos ${ }^{2-5}$.

A Resolução da Diretoria Colegiada - ANVISA (RDC) $n^{\circ} 11$ (2014) exalta que a "desinfecção: é um processo físico ou químico, de destruição de microrganismos na forma vegetativa, aplicado a superfícies inertes, previamente limpas". Com relação a higienização de equipamentos, a nova RDC $n^{\circ} 11$ de 11 de março de 2014, no parágrafo único do artigo 38, trata do equipamento de hemodiálise de reserva, que este deve passar por processo de limpeza e desinfecção imediatamente antes do uso. No artigo 14, ao final de cada sessão de diálise, deve ser realizada limpeza e desinfecção do equipamento e de toda a superfície que tenha tido contato com o paciente, preconizando os locais como: cama ou cadeiras de diálise, bancadas, superfícies externas da máquina de diálise, braçadeiras, medidores de pressão arterial, estetoscópios devem ser desinfetados. A limpeza e desinfecção reduz o risco de propagação de uma infecção, aumentando a qualidade do atendimento do paciente reduzindo a sua exposição a possíveis fatores complicadores do processo ${ }^{6}$.

A adenosina trifosfato (ATP) está presente em materiais orgânicos, e é possível detectá-lo e dosá-lo através do método de bioluminescência (BL). A reação ocorre através da produção e emissão de luz por organismos vivos, nas quais as reações são catalisadas por luciferases ${ }^{7}$.

Este estudo tem como objetivo avaliar a limpeza da superfície do equipamento de hemodiálise através do método de bioluminescência com o Lightning MVP ICON, antes e depois do procedimento de higienização.

\section{MATERIAIS E MÉTODOS}

Este é um estudo transversal e quantitativo, realizado nos meses de novembro e dezembro do ano de 2014, na Unidade de Hemodiálise do Hospital São Lucas da Pontifícia Universidade Católica do Rio Grande do Sul, Brasil. A unidade conta com 20 máquinas de hemodiálise da marca
Fresenius 2008 E $^{\circledR}$ (Fresenius Medical Care, Hamburg, Alemanha). Foram realizadas as coletas nos turnos manhã, tarde e noite, sendo analisadas 20 máquinas de hemodiálise em cada turno.

Foram selecionados quatro pontos nos equipamentos de hemodiálise por serem frequentemente tocados/manipulados pela equipe de saúde e serem um potencial carreador de microorganismos entre os profissionais, sendo eles: superfície da máquina, garra do hemodialisador, setas de programação e botão ON/OFF. Em cada equipamento foram avaliados estes quatro pontos em dois momentos: antes e depois da limpeza do mesmo, conferindo 160 amostras coletadas em cada turno, totalizando 480 pontos.

As coletas ocorreram ao final da sessão de hemodiálise, sendo o momento anterior realizado logo após a sessão de hemodiálise e o depois foi realizado 10 minutos após o término da limpeza da máquina. Na rotina do serviço de hemodiálise, a limpeza das máquinas é realizada com o produto que tem como princípio ativo a Glucoprotamina (Incidin ${ }^{\circledR}$ Extra N), que para a limpeza é colocado em compressa de algodão e então aplicado na superfície da máquina de hemodiálise. Não foi alterado o processo de limpeza realizada pela equipe de enfermagem.

A avaliação da limpeza da superfície do equipamento de hemodiálise foi realizada com o equipamento Lightning MVP ICON, que monitora a higienização pelo método de bioluminescência de ATP, o qual detecta resíduo biológico total indicando a efetividade da limpeza de superfícies. Quando inserido o swab de superfície ele detecta a quantidade de luz que a reação entre a enzima e o material coletado produz, o tempo que o aparelho leva para realizar a análise da amostra é $<1$ minuto, que resulta em três classificações: passou, alerta e falha, com código de cores, respectivamente verde, amarela e vermelha.

As amostras foram coletadas com swabs pertencentes ao kit do equipamento Lightning MVP ICON, o qual possui na extremidade superior o tampão (Buffer) e outro compartimento que contém a enzima luciferina-luciferase, quando ativado o dispositivo a solução do Buffer dissolve a enzima e passa por dentro do tubo de swab que é colocado dentro do equipamento Lightning MVP ICON para que seja efetuada a leitura.

Para cada ponto de coleta utilizou-se um swab, esfregando toda a sua superfície. Na superfície da máquina foram coletadas as amostras na região superior do equipamento no canto esquerdo frontal, uma área de aproximadamente $10 \mathrm{~cm}^{2}$, na parte interna esquerda da garra, nos botões do painel de controle (setas) e no botão de ON/OFF. Os resultados quantitativos foram qualificados através das zonas de limpeza (escala numérica de zero a cinco - Figura 1). 


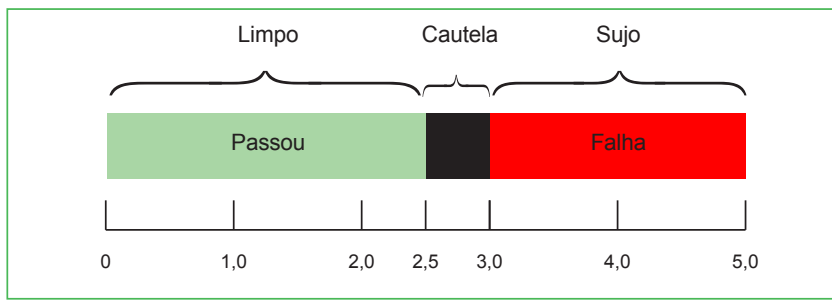

Figura 1. Escala de Zonas de Limpeza.

Foi feita análise estatística descritiva dos resultados, a distribuição de normalidade foi verificada pelo teste de Shappiro Wilk. A comparação das variáveis categóricas entre grupos independentes ocorreu pelo teste Exato de Fisher e quando a análise envolveu variáveis contínuas, utilizou-se o teste de Kruskal Wallys - Post Hoc Dunn. Na avaliação dos dados categóricos pareados foi utilizado o teste de McNemar
Browker e sobre as variáveis contínuas o teste de Wilcoxon. Os dados foram analisados no programa Statistical Package for Social Sciences versão 20.0 (SPSS Inc., Chicago, IL, USA, 2010) para Windows, sendo que, para critérios de decisão estatística adotou-se o nível de significância de 5\%. O estudo foi aprovado pela Comissão de Científica da Faculdade de Enfermagem, Nutrição e Fisioterapia da PUCRS protocolo 1412776476617 e registro no Sistema de Pesquisa da PUCRS de número 5910.

\section{RESULTADOS}

Os resultados apresentados referem-se a uma amostra de 480 pontos realizados antes e depois do procedimento de higienização nos locais pré-determinados. A distribuição absoluta e relativa para a caracterização das condições da superfície superior, setas do painel de controle, garra e do botão ON/OFF, antes e depois sobre o total da amostra e por turnos são apresentadas na Tabela 1.

Tabela 1. Distribuição absoluta e relativa para a caracterização das condições da superfície superior, setas do painel de controle, garra e botão ON/ OFF, antes e depois da limpeza sobre o total da amostra e por turnos.

\begin{tabular}{|c|c|c|c|c|c|c|c|c|c|c|c|c|c|c|c|c|}
\hline \multirow{3}{*}{ Classificações } & \multicolumn{4}{|c|}{ Superfície Superior } & \multicolumn{4}{|c|}{ Setas do painel de controle } & \multicolumn{4}{|c|}{ Garra } & \multicolumn{3}{|c|}{ Botão ON/OFF } & \\
\hline & \multicolumn{2}{|c|}{ Antes } & \multicolumn{2}{|c|}{ Depois } & \multicolumn{2}{|c|}{ Antes } & \multicolumn{2}{|c|}{ Depois } & \multicolumn{2}{|c|}{ Antes } & \multicolumn{2}{|c|}{ Depois } & \multicolumn{2}{|c|}{ Antes } & \multicolumn{2}{|c|}{ Depois } \\
\hline & $\mathbf{N}$ & $\%$ & $\mathbf{N}$ & $\%$ & $\mathbf{N}$ & $\%$ & $\mathbf{N}$ & $\%$ & $N$ & $\%$ & $\mathbf{N}$ & $\%$ & $N$ & $\%$ & $N$ & $\%$ \\
\hline \multicolumn{17}{|l|}{ Total amostra } \\
\hline Passou & 6 & 10,0 & 11 & 18,3 & 15 & 25,0 & 29 & 48,3 & 11 & 18,3 & 25 & 41,7 & 5 & 8,3 & 10 & 16,7 \\
\hline Alerta & 10 & 16,7 & 18 & 30,0 & 21 & 35,0 & 15 & 25,0 & 21 & 35,0 & 21 & 35,0 & 10 & 16,7 & 10 & 16,7 \\
\hline Falhou & 44 & 73,3 & 31 & 51,7 & 24 & 40,0 & 16 & 26,7 & 28 & 46,7 & 14 & 23,3 & 45 & 75,0 & 40 & 66,7 \\
\hline$p €$ & \multicolumn{4}{|c|}{0,062} & \multicolumn{4}{|c|}{0,033} & \multicolumn{4}{|c|}{0,011} & \multicolumn{4}{|c|}{0,427} \\
\hline \multirow{2}{*}{\multicolumn{17}{|c|}{$\begin{array}{l}\text { Turnos } \\
\text { Manhã }\end{array}$}} \\
\hline & & & & & & & & & & & & & & & & \\
\hline Passou & 3 & 15,0 & 5 & 25,0 & 7 & 35,0 & 8 & 40,0 & 5 & 25,0 & 6 & 30,0 & 2 & 10,0 & 3 & 15,0 \\
\hline Alerta & 3 & 15,0 & 4 & 20,0 & 5 & 25,0 & 5 & 25,0 & 7 & 35,0 & 9 & 45,0 & 4 & 20,0 & & \\
\hline Falhou & 14 & 70,0 & 11 & 55,0 & 8 & 40,0 & 7 & 35,0 & 8 & 40,0 & 5 & 25,0 & 14 & 70,0 & 17 & 85,0 \\
\hline$p €$ & \multicolumn{4}{|c|}{0,644} & \multicolumn{4}{|c|}{0,954} & \multicolumn{4}{|c|}{0,721} & \multicolumn{3}{|c|}{0,308} & \\
\hline \multicolumn{17}{|l|}{ Tarde } \\
\hline Passou & & & 2 & 10,0 & 4 & 20,0 & 8 & 40,0 & 5 & 25,0 & 7 & 35,0 & 2 & 10,0 & 2 & 10,0 \\
\hline Alerta & 5 & 25,0 & 4 & 20,0 & 8 & 40,0 & 5 & 25,0 & 9 & 45,0 & 6 & 30,0 & 3 & 15,0 & 4 & 20,0 \\
\hline Falhou & 15 & 75,0 & 14 & 70,0 & 8 & 40,0 & 7 & 35,0 & 6 & 30,0 & 7 & 35,0 & 15 & 75,0 & 14 & 70,0 \\
\hline$p €$ & \multicolumn{4}{|c|}{0,096} & \multicolumn{4}{|c|}{0,228} & \multicolumn{4}{|c|}{0,601} & \multicolumn{3}{|c|}{0,978} & \\
\hline \multicolumn{17}{|l|}{ Noite } \\
\hline Passou & 3 & 15,0 & 4 & 20,0 & 4 & 20,0 & 13 & 65,0 & 1 & 5,0 & 12 & 60,0 & 1 & 5,0 & 5 & 25,0 \\
\hline Alerta & 2 & 10,0 & 10 & 50,0 & 8 & 40,0 & 5 & 25,0 & 5 & 25,0 & 6 & 30,0 & 3 & 15,0 & 6 & 30,0 \\
\hline Falhou & 15 & 75,0 & 6 & 30,0 & 8 & 40,0 & 2 & 10,0 & 14 & 70,0 & 2 & 10,0 & 16 & 80,0 & 9 & 45,0 \\
\hline$p €$ & & & & & & & & & & & & & & 0,032 & & \\
\hline
\end{tabular}

$€$ : Teste de McNemar Browker. 
Tomando como base o total da amostra, ocorreu diferença estatística significativa entre as avaliações antes e depois no local das setas de programação ( $p=0,033)$, onde ocorreu um aumento significativo da classificação "Passou" no momento depois [48,3\% $(n=29)]$ quando comparado ao anterior [25,0\% ( $n=15)]$. Da mesma forma, houve uma redução significativa na classificação "Falhou" no momento depois da limpeza $[26,7 \%(n=16)]$ quando comparado ao número de casos antes $[40,0 \%(n=24)]$. Resultado semelhante ocorreu nos dados da garra $(p=0,011)$, apontando para uma redução significativa do número de falhas na avaliação depois da higienização [46,7\% $(n=28)]$ em comparação ao momento anterior [23,3 $(n=14)]$; bem como um aumento relevante da classificação "Passou" na avaliação depois $[41,7 \%(n=25)]$ em relação a antes da limpeza [18,3\% $(n=11)]$.

O ponto que apresentou maior "falha" na avaliação antes da limpeza foi o botão ON/OFF (75,0\%), seguido da superfície superior $(73,3 \%)$, que apresentaram valores acima de 50,0\%, posteriormente a garra $(46,7 \%)$ e por último as setas do painel de controle $(40,0 \%)$. Sobre os resultados referentes às condições da superfície superior da máquina e do botão ON/OFF, embora tenha-se verificado uma redução do número de falhas no momento depois da limpeza, bem como um aumento do número de casos que passaram, as diferenças não se mostraram relevantes, apontando que, as variações se devem ao acaso.

Quando os resultados foram avaliados dentro de cada turno, verificou-se que as diferenças significativas ficaram a cargo do turno da noite com uma redução expressiva no número de casos com falhas antes e depois da limpeza: superfície superior da máquina (1) antes $75,0 \%(n=15)$ vs. depois $30,0 \%(n=6), p=0,040$; setas do painel antes $40,0 \%$ $(n=8)$ vs. depois $10,0 \%(n=2), p=0,015$; garra antes $70,0 \%$ $(n=14)$ vs. depois $10,0 \%(n=2), p=0,001 ;$ ON/OFF (4) antes $80,0 \%(n=16)$ vs. depois $45,0 \%(n=9), p=0,032)$.

Para avaliar exclusivamente o número de ocorrência de falhas que está apresentado na Figura 2, foi calculado o número de vezes em que esta se fez presente nas avaliações

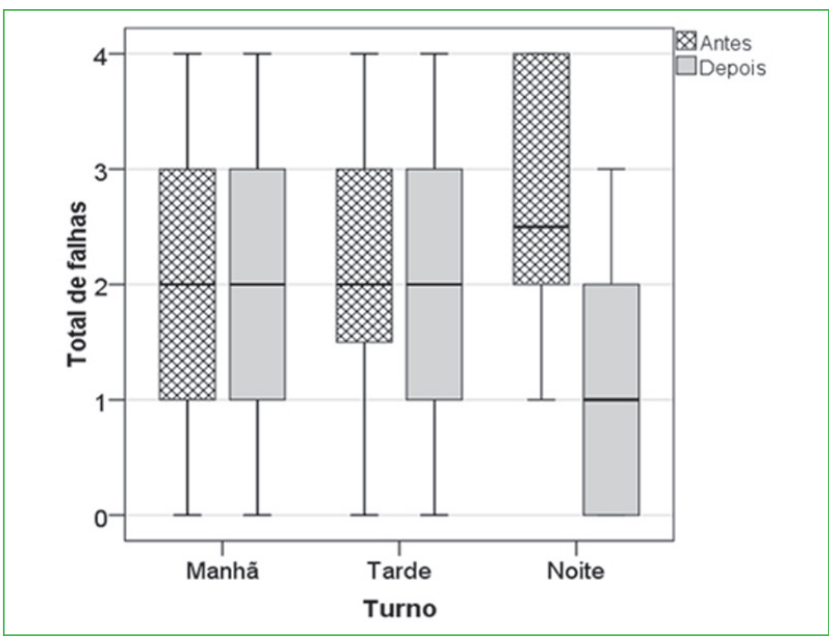

Figura 2. Número observado para o total de falhas nas avaliações antes e depois da limpeza, segundo o turno.

antes e a da limpeza nos três turnos, independentemente das 4 condições investigadas (superfície superior, setas do painel de controle, garra e botão ON/OFF). Sobre a média, desvio padrão e mediana para o número de falhas nos dois momentos avaliados, com relação ao total da amostra e por turnos, verificaram-se que, para o total da avaliação antes da limpeza $(2,4 \pm 1,1$; mediana: 2,0$)$ concentrou os maiores números de falhas em relação ao momento depois $(1,7 \pm 1,3$; mediana: 2,0). No entanto, quando esta informação foi analisada em relação aos turnos, a diferença significativa ficou a cargo da noite, onde o número de falhas mostrou-se significativamente mais elevado no momento anterior a limpeza $(2,7 \pm 1,2$; mediana: 2,5$)$ quando comparado a avaliação depois $(2,0 \pm 0,9$; mediana: 1,0$)$, desta forma apresentou significância no total de falhas entre os turnos.

Já para as medidas de tendência central e de variabilidade para o número total de falhas (antes e depois da limpeza) sobre o total da amostra e por turnos (Tabela 2), tomando como base o total de erros observados no estudo (antes e depois), a estimativa foi para uma média de erros de $4,0( \pm 2,0)$, sendo o

Tabela 2. Medidas de tendência central e de variabilidade para o número total de falhas (antes + depois da limpeza) sobre o total da amostra e por turnos.

\begin{tabular}{|c|c|c|c|c|c|c|c|}
\hline \multirow{3}{*}{ Falhas } & \multicolumn{7}{|c|}{ Medidas descritivas - Total $(n=60)$} \\
\hline & \multirow[b]{2}{*}{ Média } & \multirow[b]{2}{*}{ Desvio padrão } & \multicolumn{2}{|c|}{ Amplitude } & \multicolumn{3}{|c|}{ Quartis } \\
\hline & & & Mínimo & Máximo & $19(25 \%)$ & $\begin{array}{l}\text { Mediana } \\
20(50 \%)\end{array}$ & $30(75 \%)$ \\
\hline Total geral & 4,0 & 2,0 & 0,0 & 8,0 & 2,0 & 4,0 & 6,0 \\
\hline \multicolumn{8}{|l|}{ Turnos } \\
\hline Manhã & 4,2 & 2,1 & 1,0 & 7,0 & 2,0 & 4,5 & 6,0 \\
\hline Tarde & 4,3 & 2,1 & 0,0 & 8,0 & 3,0 & 4,5 & 5,8 \\
\hline Noite & 3,6 & 1,9 & 1,0 & 7,0 & 2,0 & 3,0 & 5,8 \\
\hline p & & & & 0,504 & & & \\
\hline
\end{tabular}

I: Teste de Kruskal Wallys - Post Hoc Dunn, onde médias seguidas de letras iguais não diferem a 5\% de significância; 
mínimo de zero e o máximo de 8 , com mediana da 4,0 erros (1--3음 quartil: 2,0-6,0), ou seja, 50\% dos casos apresentaram até 4,0 erros (e os demais 50\% mais de 2 erros), bem como, $75 \%$ dos casos observados apresentaram mais de 6 erros, ou então, 25\% apresentaram até 2 erros.

Quando esta informação foi comparada aos turnos, a maior média ocorreu no turno da tarde $(4,3 \pm 2,1$; mediana: 4,5 falhas), seguida do turno da manhã $(4,2 \pm 2,1$; mediana: 4,5$)$, ficando o turno da noite com a menor média de falhas $(3,6 \pm 1,9$; mediana: 3,0$)$. Apesar das diferenças dos turnos diurnos em comparação ao turno da noite, as diferenças significativas não se configuraram, ou seja, os três turnos estão apresentando números semelhantes para o total de falhas.

Para analisar a tendência do número de falhas, considerando-se simultaneamente os turnos e as avaliações antes e depois da limpeza, foi implementada a técnica de análise de medidas repetidas onde o resultado detectou efeito de interação $(p<0,001)$ entre avaliação de limpeza e turnos de diálise, indicando que existem variações diferenciadas entre as pontuações médias de falhas antes e depois da limpeza entre os turnos, de forma que, o turno da noite (antes $2,7 \pm 1,2$ vs. depois 1,0 00,9 ) apresentou uma redução significativamente mais expressiva no número de falhas quando comparado aos turnos da manhã (antes 2,2 $\pm 1,2$ vs. depois $2,0 \pm 1,2$ ) e da tarde (antes $2,2 \pm 1,0$ vs. depois $2,1 \pm 1,3)$, apresentados na Figura 3 .

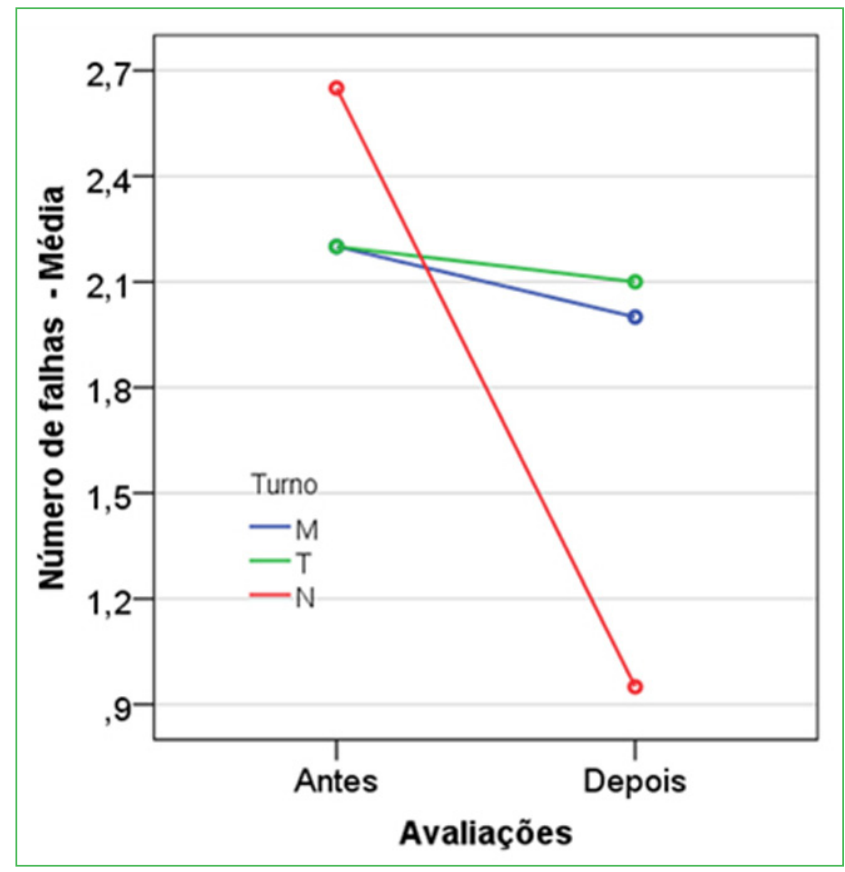

Figura 3. Média para o total de falhas nas avaliações antes e depois da limpeza, segundo o turno.

\section{DISCUSSÃO}

A limpeza de superfície é uma medida utilizada para controle de infecções, e a efetividade na desinfecção reduz os riscos de disseminação de microrganismos pelos profissionais da saúde que manipulam os materiais durante a assistência ao paciente ${ }^{8}$. Oliveira e Canettieri ${ }^{9}$ afirmam que a avaliação da limpeza por meio de bioluminescência, que verifica a presença de $A T P$, é importante no monitoramento e controle da higienização qualificando o processo empregado na limpeza de superfície de forma eficaz e mais rápida do que outros métodos como o método clássico (contagem padrão em placas pela técnica do swab) e da placa de RODAC $^{\circledR}$. O resultado deste estudo apresenta significativa diferença entre os momentos antes e depois a limpeza do equipamento de hemodiálise, o qual demonstra a redução de material biológico após o processo de limpeza da máquina, compactuando com estudos sobre o tema, que relaciona como é conclusiva a utilização de ATP na detecção de resíduos orgânicos em materiais inanimados ${ }^{10}$.

Ferreira et al. ${ }^{11}$ sugerem que modificações na técnica de limpeza em unidades hospitalares podem reduzir substancialmente nível de ATP. Obtivemos neste estudo diferença significante na redução de material orgânico das avaliações entre os turnos de trabalho. Porém, não foi qualificada a técnica empregada no procedimento de higienização das superfícies e nem os produtos utilizados para o processo de higienização. No entanto, estudos realizados que avaliam este item nos processos de desinfecção afirmam que ocorrem falhas no procedimento de limpeza relativa ao produto utilizado e a técnica empregada, sendo assim, fatores que influenciam na remoção de sujeiras visíveis e na redução de material biológico não visível'12,13.

Os achados do presente estudo sobre a contaminação nos pontos coletados não podem ser conclusivos para relacioná-los a manipulação do equipamento, pois os pontos botão ON/OFF e superfície superior apresentaram maior presença de ATP na etapa anterior a limpeza, sendo que a superfície superior não é muito manipulada com relação ao botão ON/OFF. Cordeiro et al. ${ }^{14}$, relacionam a contaminação com a manipulação de materiais e superfícies, comparando os microrganismos encontrados nestes materiais com a microbiota normal e transitória da pele.

A utilização do método Lightning MVP ICON para avaliação da limpeza da superfície do equipamento de hemodiálise permitiu observar diminuição significativa do número de falhas de limpeza após higienização e ainda redução expressiva do número de falhas nos procedimentos realizados no turno da noite quando comparados com os turnos da manhã e tarde. 
O presente estudo não identificou qual tipo de material biológico encontrado nas superfícies, sendo que o ATP está presente em diversas matérias orgânicas não somente em microrganismos. No entanto a identificação do material encontrado é um importante indicador para controle de infecções e para que assim sejam realizadas intervenções mais apropriadas. Também não foi possível esclarecer quanto ao processo de limpeza empregado na higienização de superfícies, para que se possa identificar a eficácia do produto aliado com a técnica utilizada. Então, este estudo serve de alerta para a necessidade de novas pesquisas sobre a técnica e produtos empregados na limpeza de superfícies.

\section{REFERÊNCIAS}

1. Fram D, Taminato M, Ponzio V, Manfredi SR, Grothe C, Batista RE, Belasco, A, Barbosa, D. Risk factors for morbidity and mortality of bloodstream infection in patients undergoing hemodialysis: a nested case-control study. BMC Res Notes. 2014; 7:882. http://dx.doi. org/10.1186/1756-0500-7-882

2. Pincock T, Bernstein P, Warthman S, Holst E. Bundling hand hygiene interventions and measurement to decrease health care-associated infections. Am J Infect Control. 2012; 40(4 Suppl 1):S18-27. http:// dx.doi.org/10.1016/j.ajic.2012.02.008

3. Carling PC, Bartley JM. Evaluating hygienic cleaning in health care settings: what you do not know can harm your patients. Am J Infect Control. 2010; 38(5 Suppl 1):S41-50. http://dx.doi.org/10.1016/j. ajic.2010.03.004

4. Otter JA, Yezli S, French GL. The role played by contaminated surfaces in the transmission of nosocomial pathogens. Infection control and hospital epidemiology. Infect Control Hosp Epidemiol. 2011; 32(7):687-99. http://dx.doi.org/10.1086/660363

5. Otter JA, Yezli S, Salkeld JA, French GL. Evidence that contaminated surfaces contribute to the transmission of hospital pathogens and an overview of strategies to address contaminated surfaces in hospital settings. Am J Infect Control. 2013; 41(5 Suppl):S6-11. http://dx.doi. org/10.1016/j.ajic.2012.12.004
6. Agência Nacional de Vigilância Sanitária. Resolução da Diretoria Colegiada, RDC n 11, de 13 de Março de 2014. [online]. Brasília, DF: ANVISA; 2014.

7. Hou C, Liu YJ, Ferré N, Fang WH. Understanding bacterial bioluminescence: a theoretical study of the entire process, from reduced flavin to light emission. Chemistry. 2014; 20(26):7979-86 http://dx.doi.org/10.1002/chem.201400253

8. Ferreira AM, Barcelos LS, Rigotti MA, de Andrade D, Andreotti JT, Almeida MG. Areas of hospital environment: a possible underestimated microbes reservoir?-integrative review. J Nurs UFPE. 2013; 7(5):4171-82. http://dx.doi.org/10.5205/reuol.4134-327431-SM-1.0705esp201310

9. Oliveira T, Canettieri ACV. Eficiência dos métodos microbiológicos e de ATP: bioluminescência na detecção da contaminação de diferentes superfícies. Rev Inst Adolfo Lutz. 2010; 69(4): 467-74.

10. Oliveiral AC, Vianall REH. Adenosina trifosfato bioluminescência para avaliação da limpeza de superfícies: uma revisão integrativa. Rev Bras Enferm. [periódico online]. 2014; 67(6):987-993. http:// dx.doi.org/10.1590/0034-7167.2014670618

11. Ferreira AM, Andrade D, Rigotti MA, Ferreira MVF. Condições de limpeza de superfícies próximas ao paciente, em uma unidade de terapia intensiva. Rev Latino-Am Enfermagem [online]. 2011;19(3):557-564. http://dx.doi.org/10.1590/S010411692011000300015

12. Silva NO, Ferraz PC, Silva AL, Malvezzi CK, Poveda VB. Avaliação da técnica de desinfecção dos colchões de uma unidade de atendimento a saúde. REME Rev Min Enferm. [online]. 2011;15(2):242-247. http://www.dx.doi.org/S1415-27622011000200012

13. Oliveira AC, Viana REH, Damasceno QS. Contamination of hospital mattresses by microorganisms of epidemiological relevance: an integrative review. J Nurs UFPE [online]. 2012;7(1):236-45. http:// dx.doi.org/10.5205/reuol.3049-24704-1-LE.0701201332

14. Cordeiro ALAO, Oliveira MMC, Fernandes JD, Barros CSMA, Castro LMC. Contaminação de equipamentos em unidade de terapia intensiva. Acta Paul Enferm. [online]. 2015; 28(2):160-5. http:// dx.doi.org/10.1590/1982-0194201500027 